\title{
No evidence for antibodies to mycobacterial A60 antigen in Crohn's disease sera by enzyme-linked immunoabsorbent assay (ELISA)
}

\author{
J. J. McFADDEN and C. HOUDAYER*
}

Department of Surgery, St George's Hospital Medical School, Cranmer Terrace, London, SW17 $1 E R$ and "Anda Biologicals, 37, rue de la course, 67000 Strasbourg, France

Summary. Sera from patients with Crohn's disease were tested with an ELISA system for antibodies to antigen A60 prepared from Mycobacterium bovis (BCG), $M$. avium and $M$. paratuberculosis. No evidence was found for significantly high titres of antibody to these antigens.

\section{Introduction}

Mycobacteria have been implicated as possible aetiological agents in Crohn's disease (Burnham et al., 1978). Recently, a slow-growing mycobactindependent mycobacterium was isolated from Crohn's disease tissue (Chiodini et al., 1984). The organism was similar in its cultural and biochemical properties to Mycobacterium paratuberculosis - the causative agent of Johne's disease in ruminantsand has been shown by DNA hybridisation (McFadden et al., 1987a) and by use of DNA probes that distinguish between $M$. paratuberculosis and $M$. avium, to be indistinguishable from $M$. paratuberculosis (McFadden et al., 1987b). Thayer et al. (1984) used an enzyme-linked immunoabsorbent assay (ELISA) to detect antibody to a crude preparation of $M$. paratuberculosis antigen and found increased antibody titres to the antigen in $23 \%$ of Crohn's disease patients. Also, Grange et al. (1980), also using an ELISA test, had found increased antibody titres to a soluble crude antigen preparation of $M$. tuberculosis in Crohn's disease sera. In both these studies significant mycobacterial antibody titres were found in some control sera. More recently, Cho et al. (1986) found no evidence for increased antibody titres in Crohn's disease sera to either a crude sonicate of, or a purified speciesspecific glycolipid from, M. paratuberculosis. However, in this study, a high proportion $(25-58 \%$ ) of control patients gave positive reactions to the crude sonicate antigen, whereas no sera gave reactions to

Received 9 Jan. 1987; accepted 29 Jan. 1987. the purified glycolipid antigen. Furthermore, no positive disease controls were used, so the significance of the negative results is uncertain.

The use of a purified and characterised antigen preparation could possibly provide a more sensitive and discriminating test than those in which crude antigen has been used. Such an assay would be useful as a non-invasive diagnostic test for Crohn's disease. To explore this possibility we have used an ELISA to measure antibody levels to A60 antigena membrane glycoprotein that is found in most mycobacteria (Cocito, 1985)-prepared from $M$. bovis (BCG), $M$. avium, and $M$. paratuberculosis in sera from Crohn's disease patients. A similar test with A60 antigen prepared from $M$. bovis (BCG) gave positive titres in a high proportion of sera from tuberculosis patients $(C$. Cocito, personal communication).

\section{Materials and methods}

\section{Sera}

Control sera (20) were obtained from patients attending hospital and whose blood had been sent for analysis at the National Center for Blood Transfusion (Strasbourg). For this group, sera from patients attending the Pneumology Department were discarded in order not to introduce potential positives. Tuberculosis sera (12) were obtained from patients attending a pneumology clinic (Paris). Three reference tuberculosis sera were samples previously characterised as giving strongly positive, positive and weakly positive optical densities in ELISA with $M$. bovis (BCG) A60 antigen. A negative reference 
serum was previously characterised as giving no reaction against the A60 antigens tested. Crohn's disease sera (20) were obtained from patients being treated at the Department of Surgery, St George's Hospital Medical School, London. Most patients had clinically active disease.

\section{ELISA assays}

A60 antigens were prepared as described by Cocito (1985) from $M$. bovis strain BCG, M. paratuberculosis strain $2 \mathrm{E}$, and $M$. avium strain $\mathrm{D} 4$. The antigens were bound to microtitration plates at $p H 9.0$ in carbonate buffer (Cocito, 1985). Reference sera were introduced into each experiment-one negative serum and three positive sera in order to standardise the tests for day to day fluctuations. The unknown and reference sera were added $(100 \mu \mathrm{l})$ at a dilution of 1 in 100 and incubated for $60 \mathrm{~min}$ at room temperature. The plates were washed and bound antisera were detected with affinity purified chicken anti-human IgG conjugated to peroxidase (100 $\mu \mathrm{l}, 60 \mathrm{~min}$ at room temperature). Substrate (orthophenylene diamine) at $p \mathrm{H} 5.5$ plus $\mathrm{H}_{2} \mathrm{O}_{2}$ was added, incubated for $15 \mathrm{~min}$ at room temperature and the optical density values were read at $492 \mathrm{~nm}$ by a Titertek Multiscan at $492 \mathrm{~nm}$. The readings were scored as negative $(-)$, weakly positive $(+/-)$, positive $(+)$, or strongly positive $(++)$ by comparison with the reference sera.

\section{Results}

Sera from the patients with Crohn's disease were first tested for antibody against A60 antigen prepared from $M$. bovis (BCG), and $M$. paratuberculosis (table I). Only one of the Crohn's disease sera (no. 6) yielded a significant OD against the antigens tested, showing identical reactivity against A60 antigen from $M$. bovis (BCG) and $M$. paratuberculosis. Three other antisera (nos. 2, 4 and 20) gave weaker, but not significant values. The patients whose sera yielded positive values could not be distinguished from the others on the basis of disease activity, site of involvement, duration, or treatment of disease. Sera from the control group gave a similar pattern of reactivity against the $M$. bovis (BCG) A60 antigen, although three had significantly positive results (table II).

The same Crohn's disease sera were next tested for antibody against A60 antigen purified from $M$. avium and twelve tuberculosis sera were tested in the same experiment. The results are shown in table III. Tuberculosis sera, as expected, gave positive reactions with the $M$. bovis (BCG) A60 antigen, but also gave positive results with $M$. avium A60 antigen. The Crohn's disease sera presented a similar pattern of reactivity with $M$. avium A60
Table I. Reactivity of Crohn's disease sera with A60 antigen prepared from $M$. bovis (BCG) and $M$. paratuberculosis in an ELISA

\begin{tabular}{|c|c|c|c|c|}
\hline \multirow[b]{3}{*}{ Serum no. } & \multicolumn{4}{|c|}{ Reaction of serum with A60 antigen from } \\
\hline & \multicolumn{2}{|r|}{ M. bovis } & \multicolumn{2}{|c|}{ M.paratuberculosis } \\
\hline & OD & Classification & OD & Classification \\
\hline Reference sera & & & & \\
\hline Neg. & 0.07 & - & $0 \cdot 08$ & - \\
\hline TB1 & $0 \cdot 205$ & $+1-$ & - & - \\
\hline \multicolumn{5}{|l|}{ Crohn's sera } \\
\hline 1 & 0.03 & & 0.04 & \\
\hline 2 & 0.07 & & $0 \cdot 24$ & $+1-$ \\
\hline 3 & 0.00 & & 0.03 & \\
\hline 4 & $0 \cdot 24$ & $+1-$ & $0 \cdot 17$ & \\
\hline 5 & 0.05 & & $0 \cdot 08$ & \\
\hline 6 & $0 \cdot 37$ & + & $0 \cdot 37$ & + \\
\hline 7 & 0.07 & & $0 \cdot 03$ & \\
\hline 8 & 0.02 & & 0.04 & \\
\hline 9 & 0.01 & & 0.00 & \\
\hline 10 & 0.03 & & 0.08 & \\
\hline 11 & 0.00 & & $0 \cdot 00$ & \\
\hline 12 & 0.00 & & 0.00 & \\
\hline 13 & 0.01 & & 0.02 & \\
\hline 14 & 0.02 & & 0.08 & \\
\hline 15 & 0.00 & & 0.08 & \\
\hline 16 & 0.06 & & $0 \cdot 11$ & \\
\hline 17 & $0 \cdot 12$ & & 0.18 & \\
\hline 18 & 0.11 & & $0 \cdot 16$ & \\
\hline 19 & 0.02 & & 0.04 & \\
\hline 20 & $0 \cdot 16$ & & $0 \cdot 21$ & $+1-$ \\
\hline
\end{tabular}

antigen as with $M$. bovis (BCG) and $M$. paratuberculosis A60 antigens. Sera nos. 4 and 6 were positive and nos. 2, 3, 10 and 20 showed weak reactivity.

\section{Discussion}

No evidence was found for significant levels of reactivity of Crohn's disease sera with A60 antigen purified from $M$. avium, $M$. bovis or $M$. paratuberculosis. The reference tuberculosis sera gave positive values in each test and the control sera gave few positives, demonstrating the specificity of the test. The positive values obtained for the Crohn's and control sera could have been due to previous exposure to $M$. tuberculosis or other environmental mycobacteria. Similar tests with sera from tuberculosis patients gave positive values against A60 antigen prepared from $M$. tuberculosis with most sera tested (M. Baelden, personal communication). In addition, the results with the tuberculosis sera included in table III indicate that the test is positive even when the test antigen (M. avium) differs from the sensitising antigen (M. tuberculosis or M. bovis), 
Table II. Reactivity of control sera with A60 antigen prepared from $M$. bovis (BCG)

\begin{tabular}{|c|c|c|}
\hline \multirow[b]{2}{*}{ Serum no. } & \multicolumn{2}{|c|}{$\begin{array}{l}\text { Reactivity with } M \text {. bovis } \\
\text { A60 }\end{array}$} \\
\hline & OD & Classification \\
\hline Reference sera & & \\
\hline Neg. & 0.25 & - \\
\hline TB1 & 0.35 & $+1-$ \\
\hline TB2 & 0.69 & + \\
\hline Control sera & & \\
\hline 1 & $0 \cdot 21$ & \\
\hline 2 & 0.25 & \\
\hline 3 & 0.49 & + \\
\hline 4 & $0 \cdot 20$ & \\
\hline 5 & $0 \cdot 22$ & \\
\hline 6 & $0 \cdot 15$ & \\
\hline 7 & $0 \cdot 50$ & + \\
\hline 8 & $0 \cdot 37$ & $+1-$ \\
\hline 9 & 0.17 & \\
\hline 10 & $0 \cdot 15$ & \\
\hline 11 & $0 \cdot 17$ & \\
\hline 12 & 0.48 & + \\
\hline 13 & $0 \cdot 20$ & \\
\hline 14 & $0 \cdot 29$ & \\
\hline 15 & $0 \cdot 18$ & \\
\hline 16 & 0.29 & \\
\hline 17 & 0.45 & $+1-$ \\
\hline 18 & $0 \cdot 36$ & $+1-$ \\
\hline 19 & $0 \cdot 18$ & \\
\hline 20 & $0 \cdot 15$ & \\
\hline
\end{tabular}

showing a high degree of cross reactivity to A60 antigen.

These results demonstrate that Crohn's disease patients do not have increased levels of antibody to A60 antigen prepared from $M$. bovis, $M$. paratuberculosis or $M$. avium. The results also show that in a known mycobacterial disease (tuberculosis), sera cross-react with antigen prepared from $M$. avium and $M$. paratuberculosis. It seems unlikely, therefore, that the lack of reactivity of Crohn's disease sera with the A60 antigens could be due to insufficient cross-reactivity of Crohn's diseaseinvolved mycobacteria with the tested antigens. This does not however exclude the possibility of mycobacterial involvement in Crohn's disease. Many patients may be anergic to the mycobacterial antigens as sometimes occurs in leprosy. Alternatively, A60 antigens may not be exposed to the immune system in Crohn's disease, so that patients may not develop antibody. When mycobacteria were isolated from Crohn's-disease tissue they first appeared as extremely slow-growing, possibly cellwall defective forms (Burnham et al., 1978; Chiod-
Table III. Reactivity of Crohn's disease and tuberculosis sera with A60 antigen prepared from $M$. avium

\begin{tabular}{|c|c|c|}
\hline \multirow[b]{2}{*}{ Serum no. } & \multicolumn{2}{|c|}{$\begin{array}{l}\text { Reactivity with } M . a v- \\
\text { ium A60 }\end{array}$} \\
\hline & OD & Classification \\
\hline \multicolumn{3}{|c|}{ Tuberculosis sera } \\
\hline 1 & $1 \cdot 58$ & ++ \\
\hline 2 & $0 \cdot 61$ & ++ \\
\hline 3 & $0 \cdot 41$ & + \\
\hline 4 & $0 \cdot 88$ & ++ \\
\hline 5 & $0 \cdot 72$ & ++ \\
\hline 6 & $0 \cdot 66$ & ++ \\
\hline 7 & 0.96 & ++ \\
\hline 8 & $1 \cdot 00$ & ++ \\
\hline 9 & $1 \cdot 05$ & ++ \\
\hline 10 & $1 \cdot 31$ & ++ \\
\hline 11 & $1 \cdot 20$ & ++ \\
\hline 12 & $1 \cdot 26$ & ++ \\
\hline \multicolumn{3}{|l|}{ Reference sera } \\
\hline Neg. & $0 \cdot 15$ & - \\
\hline TB2 & $0 \cdot 42$ & + \\
\hline TB3 & $1 \cdot 35$ & ++ \\
\hline \multicolumn{3}{|l|}{ Crohn's sera } \\
\hline 1 & $0 \cdot 22$ & - \\
\hline 2 & $0 \cdot 33$ & $+1-$ \\
\hline 3 & $0 \cdot 30$ & $+1-$ \\
\hline 4 & $0 \cdot 65$ & + \\
\hline 5 & $0 \cdot 27$ & - \\
\hline 6 & $0 \cdot 54$ & + \\
\hline 7 & $0 \cdot 21$ & - \\
\hline 8 & $0 \cdot 21$ & - \\
\hline 9 & $0 \cdot 23$ & - \\
\hline 10 & $0 \cdot 30$ & $+1-$ \\
\hline 11 & $0 \cdot 27$ & - \\
\hline 12 & $0 \cdot 21$ & - \\
\hline 13 & $0 \cdot 17$ & - \\
\hline 14 & $0 \cdot 20$ & - \\
\hline 15 & $0 \cdot 18$ & - \\
\hline 16 & $0 \cdot 27$ & - \\
\hline 17 & $0 \cdot 21$ & - \\
\hline 18 & $0 \cdot 22$ & - \\
\hline 19 & $0 \cdot 21$ & - \\
\hline 20 & 0.39 & $+1-$ \\
\hline
\end{tabular}

ini et al., 1984). These forms may not express A60 antigen. The A60 antigen of $M$. bovis is preponderant during exponential multiplication and recedes during declining phases (Cocito, 1985). Also, sera from tuberculosis patients in a progressive phase of the disease react readily in this system (C. Cocito, personal communication).

The results presented here suggest that in the experiments described by Thayer et al. (1984) and Grange et al. (1980), who obtained significant antibody levels in Crohn's disease sera with $M$. 
paratuberculosis and $M$. tuberculosis crude cell homogenates as antigen sources, the reacting antigen is unlikely to have been the A60 glycoprotein; therefore, an ELISA test based on the A60

\section{REFERENCES}

Burnham W R, Lennard-Jones J E, Stanford J C, Bird R G 1978 Mycobacteria as a possible cause of inflammatory bowel disease. Lancet 2:693-696.

Chiodini R J, van Kruiningen H J, Thayer W R, Merkal R S, Coutu J A 1984 Possible role of mycobacteria in inflammatory bowel disease. I. An unclassified Mycobacterium species isolated from patients with Crohn's disease. Digestive Diseases Science 29: 1073-1079.

Cho Sang-Nae, Brennan P J, Yoshimura H H, Korelitz B I, Graham D Y 1986 Mycobacterial etiology of Crohn's disease: serologic study using common mycobacterial antigens and a species-specific glycolipid antigen from Mycobacterium paratuberculosis. Gut 27:1353-1356.

Cocito C 1985 Properties of antigen 60 from Mycobacterium bovis BCG. Proceedings of the 20th Joint Conference on Tuberculosis. National Institute of Health, Bethesda, MD, USA, pp 224-226.

Grange J M, Gibson J, Nassau E, Kardjito T 1980 Enzyme- glycoprotein has no value in the diagnosis of Crohn's disease.

This work was supported by Action Research for the Crippled Child.

linked immunosorbent assay (ELISA). A study of antibodies to Mycobacterium tuberculosis in the $\operatorname{IgG}, \operatorname{IgA}$ and $\operatorname{IgM}$ classes in tuberculosis, sarcoidosis and Crohn's disease. Tubercle 61 : 145-152.

McFadden J J, Butcher P D, Chiodini R J, Hermon-Taylor J $1987 a$ Determination of genome size and DNA homology between an unclassified Mycobacterium species isolated from patients with Crohn's disease and other mycobacteria. Journal of General Microbiology 133:211-214.

McFadden J J, Butcher P D, Chiodini R J, Hermon-Taylor J $1987 b$ Use of DNA probes to distinguish between mycobacterial species: Crohn's disease-isolated mycobacteria are identical to Mycobacterium paratuberculosis. Journal of Clinical Microbiology 25: 798-801.

Thayer W R, Coutu J A, Chiodini R J, van Kruiningen H J, Merkal R S 1984 Possible role of mycobacteria in inflammatory bowel disease. II. Mycobacterial antibodies in Crohn's disease. Digestive Diseases Science 29:10801085. 